\title{
PENGARUH MODEL PEMBELAJARAN PEER TUTORING UNTUK MENINGKATKAN KEMAMPUAN KOMUNIKASI MATEMATIS SISWA
}

\author{
Elisabeth I.M.Faot*, Samuel .I. Leton, Wilfridus B.N.Dosinaeng \\ Universitas Katolik Widya Mandira Kupang \\ *elisabethfaot@gmail.com,letonsamuel@gmail.com,wilfridusdosinaeng@gmail.com
}

Dikirim: 13 Desember 2019. Diterima: 23 Januari 2020. Dipublikasikan: 31 Januari 2020

\begin{abstract}
ABSTRAK
penelitian ini bertujuan untuk mengetahui bagaimana pelaksanaan model pembelajaran peer tutoring dan pengaruh terhadap peningkatan komunikasi matematis pada pokok pembahasan persamaan lingkaran di SMAK Sint Carolus Kupang tahun ajaran 2019/2020. Penelitian ini dilakukan oleh siswa kelas XI IPA ${ }^{1}$ yang berjumlah 26 orang siswa.instrumen yang digunakan dalam penelitian ini yaitu observasi dan tes peningkatan komunikasi siswa sebanyak 3 butir soal berbentuk uraian. Teknik analisis data yang digunakan dalam penelitian ini yaitu hasil observasi pencapaian indikator uji-t dan $N$-Gain berdasarkan hasil observasi dan pencapaian indikator, diperoleh peningkatan komunikasi matematis tergolong kategori tinggi berdasarkan perhitungan uji-t menunjukkan $t_{\text {hitung }}=18.260$ dan $t_{\text {tabel }}=0.059$ pada taraf signifikan 5\% yang berarti $\mathrm{t}_{\text {hitung }}>\mathrm{t}_{\text {tabel }}$, maka $\mathrm{H}_{0}$ ditolak dan $\mathrm{H}_{\mathrm{a}}$ diterima. Berdasarkan perhitungan Uji $\mathrm{N}$-Gain menunjukkan rata-rata yaitu 19,82 sedangkan hasil perhitungan nilai $\mathrm{N}$-Gain yaitu 0.762307692 termasuk dalam kategori tinggi sehingga dapat diambil kesimpulan bahwa ada pengaruh model pembelajaran peer tutoring terhadap peningkatan komunikasi matematis siswa.
\end{abstract}

Kata kunci: Peer Tutoring, Kemampuan Komunikasi Matematis

ABSTRACT

This study aims to find out how the implementation of the peer tutoring learning model and the effect on improving mathematical communication on the subject of circle equation discussion at Sint Carolus Kupang Senior High School in 2019/2020 school year. This research was conducted by students of class XI IPA1, amounting to 26 students. The instruments used in this study were observation and improvement tests of student communication by 3 items in the form of description. Data analysis techniques used in this study are the results of observations of the achievement of t-test and N-Gain indicators based on the results of observations and achievement of indicators, obtained an increase in mathematical communication classified as high category based on t-test calculations showing tcount $=$ 18,260 and ttable $=0.059$ at significant levels $5 \%$ which means tcount $>t$ table, then $\mathrm{H} 0$ is rejected and $\mathrm{Ha}$ is accepted. Based on the calculation of the N-Gain Test shows an average of 19.82 while the results of the calculation of the N-Gain value of 0.762307692 include in the high category so that it can be concluded that there is an effect of the peer tutoring learning model on improving students' mathematical communication.

Keywords: Peer Tutoring, Mathematical Communication skills

\section{Pendahuluan}

Belajar pada hakekatnya adalah proses intraksi terhadap semua situasi yang ada di Setiap individu. Belajar dapat dipandang sebagai proses yang diarahkan kepada tujuan dan proses berbuat melalui berbagai pengalaman. Standar proses untuk satuan pendidikan dasar dasar, menengah merupakan salah satu standar yanng dikembangan sejak 2006 oleh Badan Standar Nasional Pendidikan dan pada tahun 2007 di terbitkan menjadi Peraturan Mentri Pendidikan Nasional Republik Indonesia yaitu Permendiknas RI Nomor 41 Tahun 2007

Tujuan pendidikan nasional berdasarkan UU RI NO. 20 tahun 2003 tentang Sistem Pendidikan Nasional, sebagai berikut: Pendidikan nasional bertujuan untuk berkembangnya potensi peserta didik agar 
menjadi manusia yang beriman dan bertaqwa kepada Tuhan, berakhlak mulia, sehat, berilmu, cakap, kreatif, mandiri dan menjadi warga Negara yang demokratis serta bertanggung jawab. Pada era globalisasi saat ini cendrung anak masih kurang dalam berkomunikasi di dalam kelas untuk memperlancar aktivitas belajar mengajar.

Usaha untuk meningkatkan kemampuan komunikasi terhadap siswa pastinya tidak terlepas dari aktivitas kerja sama guru dan siswa maupun siswa dengan siswa lainnya, aktivitas interaksi yang terjalin akan menumbuhkan pembelajaran yang aktif dimana siswa dengan kemampuan komunikasi yang dimiliki untuk memperoleh pengetahuan sendiri dengan bantuan guru sebagai fasilitator. Sebagai fasilitator guru dituntut untuk dapat mengembangkan kemampuan serta keterampilan.Salah satu pelajaran yang ada disekolah adalah Matematika.

Berdasarkan pengamatan peneliti pada saat melaksanakan Praktek Pengalaman Lapangan (PPL) di SMA Sint Carolus Kupang pada siswa kelas XI, rendahnya kemampuan komunikasi matematis siswa disebabkan oleh rasa malu, takut dan kurang percaya diri. Karena guru di anggap sebagai orang yang menakutkan ketika berada didalam kelas. Berkaitan dengan kemampuan komunikasi matematika. Depdiknas mengemukakan bahwa kompetensi matematika harus dimiliki SD, SMP, dan SMA salah satu diantaranya yang termaksud dalam keterampilan matematika adalah kemampuan mengkomunikasikan gagasan dengan simbol, tabel, grafik dan diagram untuk memperjelas keadaan atau masalah. Namun pada kenyataan di lapangan menunjukan bahwa kemampuan komunikasi matematika masih kurang. Hal ini dikarenakan pembelajaran matematika yang mereka alami kurang melatih kemampuan komunikasi matematis mereka salah satu model pembelajaran yang dapat meningkatkan kemampuan komunikasi matematis yaitu model pembelajaran peer tutoring. Model pembelajaran peer tutoringpada dasarnya sama dengan program bimbingan yang bertujuan untuk memberikan bantuan dalam pembelajaran terhadap siswa yang lambat, sulit dan gagal dalam belajar, agar dapat mencapai hasil belajar secara optimal bahwah pengajaran tutorialbertujuan memberikan bantuan kepada siswa lain.Di sisi lain, les privat, menggambarkan tutor sebagai rekan kerja, mengambil peran timbal balik sambil berbagi pengetahuan mereka(Duran, 2005).Dari tingkat partisipasi aktif siswa lebih tinggi.Pengajaran sebaya bermanfaat bagi pelajar cepat dan juga pelajar lambat (Vasy, 2010). Thomson mengatakan proses belajar tidak harus berasal dari guru ke siswa, melainkan dapat juga siswa saling mengajar sesama siswa lain(Hidayat, 2008). Anita Lie mengatakan pengajaran oleh rekan sebaya (peer teaching) ternyata lebih efektif dari pada pengajaran oleh guru (Hidayati, 2004). Tutor sebaya adalah jenis pembelajaran alternatif-pembelajaran di mana siswa mengadopsi sikap komitmen untuk berpikir, bernalar dan bertukar, pengetahuan(Luca, 2002).

Dalam pembelajaran matematika, siswa dituntut untuk mampu berpikir dan bernalar tentang matematika dan mengungkapkan hasil pemikiran mereka secara lisan maupun dalam bentuk tulisan (NCTM, 2000). Kemampuan siswa dalam menyampaikan ide pemikirannya kepada orang lain baik secara lisan maupun tulisan merupakan kemampuan komunikasi matematis. Ide pemikiran tersebut bisa berupa konsep, rumus, atau strategi menyelesaikan masalah.

Kemampuan komunikasi matematis siswa mencerminkan seberapa jauh pemahaman matematis dan letak kesalahan konsep siswa (NCTM, 2000).keterampilan komunikasi menjadi penting ketika diskusi di antara siswa dilakukan, di mana siswa diharapkan untuk memberitakan, menjelaskan, menjelaskan, mendengar, bertanya, dan bekerja sama sehingga dapat membawa siswa pada pemahaman yang mendalam tentang matematika(Within, 1992). Oleh karena itu guru perlu mengetahui kemampuan komunikasi matematis siswa dalam pembelajaran matematika. Untuk memperoleh siswa dengan kemampuan komunikasi matematis yang baik, dibutuhkan sebuah strategi pembelajaran yang dapat mengeksplorasikan komuniksai matematis siswa. Sebuah metode pembelajaran yang dapat mengeksplorasikan kemampuan komunikasi matematis siswa ialah model pembelajasran yang mampu mengembangkan dan mengeksplorasi aspek - aspek komunikasi.

Ada lima aspek komunikasi yaitu (1) representing (representasi), (2) listening (mendengar), (3) reading ( membaca). (4) discussing ( diskusi), (5) writing ( menulis) (Irianto, 2003). 


\section{Metode Penelitian}

Jenis penelitian yang digunakan adalah penelitian kuantitatif dengan metode eksperimen semu dengan desain eksperimen yaitu : One - group pretest - posttest design

Tabel 1.Desain eksperimen One-group pretest-postest design

\begin{tabular}{|c|c|c|c|}
\hline Sampel & Pretest & Perlakuan & Posttest \\
\hline Kelas eksperimen & $O_{1}$ & $X$ & $O_{2}$ \\
\hline
\end{tabular}

(Lestari, 2015)

Penelitian ini dilaksanakan di kelas XI IPA ${ }^{1}$ SMA Sint Carolus Kupang, penelitian ini dilaksanakan pada semester ganjil tahun ajaran 2019/2020. Populasi dalam penelitian ini yaitu seluruh siswa kelas XI Minat IPA .sampel penelitian ini adalah satu kelas yang diambil dengan teknik pengambilan sampel cluster sampling teknik pengumpulan data yang digunakan dalam penelitian ini berupa observasi nonpartisipan dan tes. Observasi dilakukan oleh dua orang pengamat untuk melihat aktivitas tutor dan siswa. Melihat aktivitas tutor didalam kelompok didkusi dan melihat aktivitas siswa bertanya kepada tutor didalam kelompok.Teknik analisis data yang digunakan yaitu uji normalitas untuk melihat data berdistribusi normal atau data tidak berdistribusi normal. Dan pengujian hipotesis. Untuk melihat peningkatan kemampuan komunikasi matematis digunakan uji $N$-Gain untuk melihat ada peningkatan kemampuan komunikasi matematis berdasarkan hasil tes

\section{Hasil Penelitian dan Pembahasan}

Hasil Analisis Data Kuantitatif

Skor capaian indicator pelaksanaan pembelajaran dengan menerapkan model pembelajaran peer tutoring terhadap peningkatan komunikasi matematis dapat dilihat pada tabel berikut:

Tabel 2 Capaian Indikator Pelaksanaan Pembelajaran

\begin{tabular}{|c|c|c|c|}
\hline & $\begin{array}{c}\text { Skor } \\
\text { pengamat I }\end{array}$ & $\begin{array}{c}\text { Skor } \\
\text { pengamat II }\end{array}$ & Capaian Indikator \\
\hline Pembelajaran 01 & 32 & 32 & $\frac{64}{72} \times 100 \%=88,88$ \\
\hline Pembelajaran 02 & 33 & 32 & $\frac{65}{72} \times 100 \%=90,27$ \\
\hline Rata-rata & 90,23 & 88,9 & $\frac{179,13 \%}{2}=89,6 \%$ \\
\hline
\end{tabular}

Berdasarkan tabel diatas maka diagram indicator pencapaiannya sebagai berikut:

Tabel di atas, capaian indikator pelaksanaan pembelajaran matematika dengan model pembelajaran peer tutoring yaitu 89,6\% hasil ini bila di konfirmasikan dengan tabel 3.2 masuk dalam kriteria sangat baik atau terlaksana dengan sangat baik, dimana semua langkah-langkahnya dilaksanakan. Secara ringkas, capaian indikator pelaksanaan pembelajaran dengan model pembelajaran peer tutoring 
Diagram1. Pelaksanaan pembelajaran dengan model pembelajaran peer tutoring

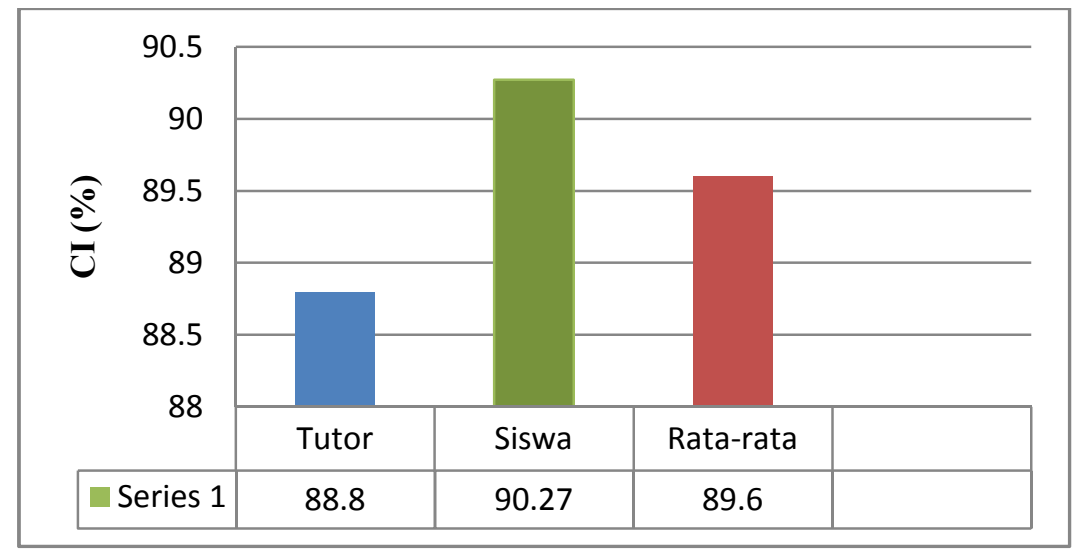

Berdasarkan diagram di atas, capaian indikator pelaksanaan pembelajaran matematika dengan model pembelajaran peer tutoring pada pembelajaran 01 yaitu $88,8 \%$ hasil ini bila di konfirmasikan dengan tabel 3.2, masuk kriteria baik, sedangkan pembelajaran 02 yaitu $90,27 \%$ hasil ini bila di konfirmasikan dengan tabel 3.2. masuk kriteria sangat baik. Secara keseluruhan bila diratakan capaian indikator pelaksanaan pembelajaran matematika dengan model pembelajaran peer tutoring yaitu 89,6 \% dan bila di konfirmasikan dengan tabel 3.2. masuk dalam kriteria baik, dimana sebagian besar langkahlangkah pembelajaran peer tutoring dilaksanakan

\section{Diagram 2 Analisis CI butir soal posttest}

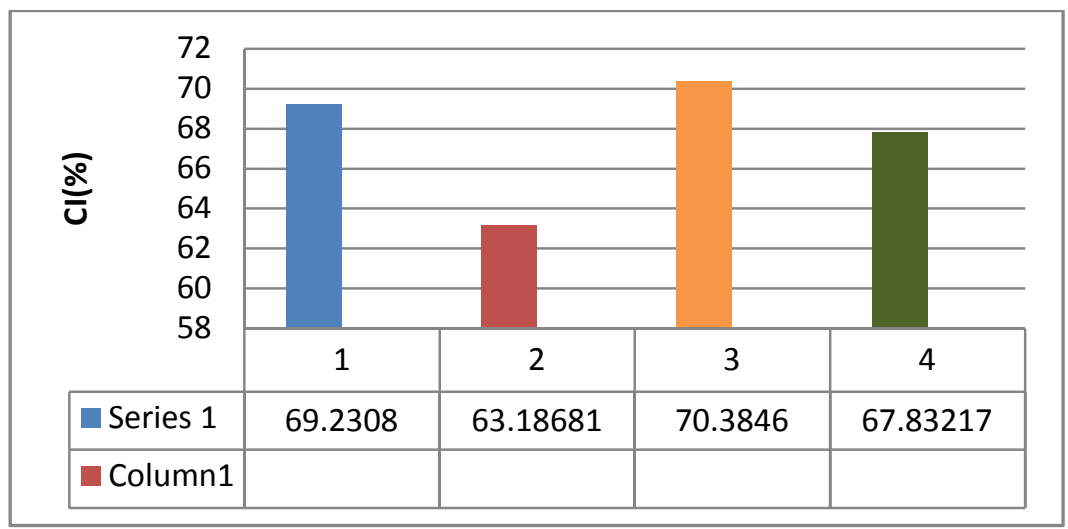

Berdasarkan diagram diatas, Capaian indikator komunikasi matematis dengan model pembelajaran peer tutoring yaitu

Pada butir soal nomor 1 dan 2 berturut-turut yaitu $69.2308 \%$ dan $63.18681 \%$. kedua hasil tersebut bila di konfirmasikan dengan tabel 3.3, masuk dalam kriteria cukup baik

Selanjutnya, untuk doal nomor 3, yaitu 70.3846 \%. Hasil ini bila di konfirmasikan dengan tabel 3.3, masuk dalam kriteria cukup baik.

Secara keseluruhan bila di rata-ratakan capaian indikator komunikasi matematis dalam model pembelajara peer tutoring yaitu $67.83217 \%$, bila di konfirmasikan dalam tabel 3.3 di kategorikan cukup baik.

Dengan demikian, komunikasi matematis siswa setelah mengikuti pelajaran dalam model pembelajaran peer tutoring tercapai dengan predikat cukup baik. 
Untuk menguji kebenaran hipotesis penelitian, data yang digunakan adalah data primer yaitu nilai pretest dan posttest pada kelas eksperimen pengelolaan data dilakukan dengan menggunakan program SPSS Versi 22.0.

\section{Uji Normalitas}

Hasil analisis SPSS untuk uji normalitaspada data pretest diperoleh nilai Asymp.Sig.(2-tailed) = $0.200>0.05$ dan $D_{\text {hitung }}=0.181<D_{\text {tabel }}=0.259$. Dengan demikian, terima $H_{0}$ yang berarti data berdistribusi normal.sedangkan untuk uji normalitas pada data posttest diperoleh nilaiAsymp. Sig. (2 tailed $)=0.200>0.05$ dan $D_{\text {hitung }}=0.177<D_{\text {tabel }}=0.259$. Dengan ndemikian, terima $H_{0}$ yang berarti data berdistribusi normal.

Uji hipotesis

Dari hasil analisis SPSS diperoleh nilai nilaiAsymp.Sig. $(2-$ tailed $)=0.000$.

Sedangkan $t_{\text {hitung }}=18.260$ dengan $\mathrm{df}=n-1$, diperoleh $\mathrm{df}=25$ dengan taraf signifikan $\frac{\alpha}{2}=0.025$

diperoleh $t_{\text {tabel }}=2.060$ sig. $(2-$ tailed $)=0.000<0.05$ dan $t_{\text {hitung }}=18.260>t_{\text {tabel }}=0.059$.

Berdasarkan syarat uji t dan kriteria penerimaan dan penolakan $H_{0}$ pada bab 3 dengan taraf signifikan 5\% maka tolak $H_{0}$ dan terima $H_{a}$ yang berarti ada pengaruh model pembelajaran peer tutoring terhadap komunikasi matematis siswa

Analisis data peningkatan

Hasil analisis indeks gain ternormalisasi menunjukan kategori rendah berdasarkan kriteria nilai $\mathrm{N}$-Gain yaitu $\mathrm{N}-$ Gain $\leq 0,30$ sebanyak 0 siswa, jumlah siswa yang termaksud kedalam kategori sedang $0,30<\mathrm{N}$-Gain $<0,70$ sebanyak 10 siswa dan termaksud dalam kategori tinggi $\mathrm{N}$-Gain $\leq 0,30$ sebanyak 16 siswa berdasarkan tabel nilai $\mathrm{N}$-Gain pada lampiran 9 rata-rata nilai

N-Gain adalah 19,82 dan hasil nilai N-Gain yaitu 0,762307692 jika di konfirmasikan pada tabel 3.4 termaksud dalam kriteria tinggi.

Pembahasan

Hasil penelitian menujukkan bahwa kemampuan komunikasi matematis siswa yang diajarkan dengan model pembelajaran peer tutoring mengalami peningkatan nilai rata-rata pretest sebelum di berlakukan model pembelajaran berbeda dengan nilai rata-rata posttest. Seorang siswa lebih mudah menerima keterangan yang diberikan oleh kawan sebangku atau kawan yang lain karena tidak ada rasanya enggan atau malu untuk bertanya (Arikunto S. , 1992). Model pembelajaran peer tutoring menjadikan siswa terlatih untuk memahami serta mengkomunikasikan masalah yang dihadapi dengan tepat menuju sebuah penyelesaian. Secara umum tahapan Pembelajaran menggunakan model pembelajaran peer tutoring sudah sesuai dengan tahapan pada pedoman observasi pembelajaran dan RPP sudah disusun peneliti sebelumnya.

a. Memilih Tutor

Adapun penerapan model pembelajaran peer tutoringyang dilaksanakan sebagai berikut:

Pada pemilihan tutor dilakukan pada test pertama atau pretest, hasil pretest tersebut di peroleh 8 orang siswa yang memenuhi kriteria tetuntasan yaitu cukup baik dengan rentan nilai 55-75 berdasarkan tabel 3.3 maka dipilih 5 orang dari 8 orang

b. Pengelompokkan siswa dan diskusi kelompok

Siswa di kelompokkan menjadi 5 kelompok dan dalam setiap kelompok mempunyai kemampuan heterogen, 5 tutor yang telah dipilih desebar pada setiap kelompok dan menjadi tutor dalam kelompok selama jalanya diskusi

Tugas dari tutor yaitu membimbing setiap siswa yang belum paham tentang soal matematika di dalam kelompok.

a) Pemberian Soal 
Pada tahap ini peneliti memberikan soal berupa LKPD yang dikerjakan secara berkelompok. Dan di bimbing oleh tutor Soal yang di berikan dengan tujuan agar siswa dapat mengingat kembali dan lebih paham materi yang didiskusikan

Hal ini disebabkan karena masih banyak siswa yang masih kurang paham tentang materi yang baru saja dibahas, sehingga peneliti menguji dengan memberikan soal

b) Menyimpulkan Materi

Pada tahap ini siswa diminta untuk menyimpulkan kesimpulan yang telah mereka rumuskan. Jika masih terdapat kekeliruan dalam membuat kesimpulan maka guru akan membimbing untuk mendapatkan kesimpulan yang benar. Dengan demikian, siswa benar-benar memahami suatu konsep yang sedang dibahas. Sesuai denga teori yang telah dijabarkan pada Bab II bahwa model pembelajaran peer tutoring merupakan kooperatif, dimana penerapannya siswa dibimbing oleh tutor yang merupakan teman sendiri yang dipilih berdasarkan hasil test. Dengan melaksanakan model pembelajaran peer tutoring siswa dapat meningkatkan komunikasi matematis

Penelitian ini berlangsung selama 2 hari. Pada hari pertama sebelum melaksanakan pembelajaran, siswa diberikan soal pretest untuk dikerjakan. Setelah mengerjakan soal peneliti memulai proses pembelajaran berdasarkan model pembelajaran peer tutoring. Kegiatan selanjutnya siswa dibagi dalam 6 kelompok yang berkemampuan heterogen yang terdiri dari 5 orang, selanjutnya peneliti membagi LKPD pada masing-masing kelompok dan dikerjakan. Dalam mengerjakan soal setiap siswa dalam kelompok mempunyai inisiatif sendiri untuk saling membagi soal-soal dalam LKPD selanjutnya semua jawaban dikumpulkan untuk didiskusikan bersama dan memutuskan jawaban yang paling tepat.

Pada pertemuan kedua peneliti langsung membagi kelompok sebanyak 5 kelompok heterogen dimana pada setiap kelompok disebar setiap tutor yang dipilih berdasarkan kriteria penilaian berdasarkan pada tabel 3.3 yaitu rentan nilai dari 55-75 dari hasil pretest sehingga dipilih 5 orang tutor yang masing masing membimbing dalam setiap kelompok, tugas dari setiap tutor yaitu membimbing teman yang belum mampu dalam kelompok serta menjelaskan materi kepada setiap siswa dan mengerjakan soal yang diberikan pada setiap kelompok.

Dalam proses selama penelitian dan guru mata mata pelajaran matematika mengamatian proses diskusi dalam kelompok dan peran tutor dalam kelompok berdasarkan lembar observasi yang telah disiapkan oleh peneliti. Setelah itu peneliti memberikan soal Posttest untuk dikerjakan untuk melihat apakah dengan mengikuti pelajaran dengan model pembelajaran peer tutoring dapat meningkatkan komunikasi matematis atau menurun.

Dengan menggunakan model pembelajaran peer tutoring siswa menjadi lebih percaya diri dalam mengkomunikasikan pemahaman dan ide-ide matematis. Hal ini juga terbukti setelah data dianalisis dengan pengujian hipotesis dan diperoleh hasil bahwa ada pengaruh yang signifikan terhadap model pembelajaran peer tutoring serta ada peningkatan komunikasi matematis siswa SMAK Sint Carolus Kupang.pada materi persamaan lingkaran Tahun ajaran 2019/2020.

\section{Simpulan dan Saran}

Simpulan

Berdasarkan hasil penelitian yang dilakukan diperoleh hasil sebagai beikut:Pelaksanaan pembelajaran dengan model pembelajaran peer tutoring untuk meningkatkan komunikasi matematis siswa kelas XI IPA ${ }^{1}$ SMAK Sint Carolus Kupang mencapai 89,6\% atau terlaksana dengan sangat baik. Dimana semua langkah-langkah dilaksanakan.Ada pengaruh model pembelajaran peer tutoring terhadap peningkatan komunikasi matematis siswa kelas XI IPA ${ }^{1}$ SMAK Sint Carolus Kupang..Peningkatan komunikasi matematis siswa dengan model pembelajaran peer tutoring pada siswa kelas XI IPA ${ }^{1}$ SMAK Sint Carolus Kupang mencapai 0,762307692 atau peningkatan komunikasi matematis siswa tercapai dengan kategori tinggi.

Saran 
Berdasarkan hasil penelitian yang telah dilakukan pada mata pelajaran matematika kelas XI IPA ${ }^{1}$ Pada poko pembahasan persamaan lingkarantahun ajaran 2019/2020 maka peneliti memberikan rekomendasi sebagai berikut:

Bagi guru dan calon guru matematika agar dapat menggunakan model pembelajaran peer tutoring ini ajar sehingga dapat melibatkan siswa secara aktif dan membiasakan siswa mengeksplor kemampuannya. Bagi siswa/siswi, dengan diterapkan model pembelajaran peer tutoring diharapkan siswa harus bias meningkatkan kemampuan komunikasi matematis, kemandirian serta aktif mengikuti proses belajar mengajar

Bagi Sekolah, sebagai masukkan untuk menerapkan model pembelajaran tipe kooperatif peer tutoring untuk meningkatkan komunikasi matematis siswa

\section{Daftar Pustaka}

Arikunto, S. (1992). Pengelolaan Kelas dan Siswa. Jakarta: Rajawali.

Irianto, B. (2003). Menumbuhkembangkan kemampuan pemahaman dan komunikasi matematika siswa SMA melalui strategi Think Talk Write. Bandung: Tidak di publikasikan .

Lestari, K. E. (2015). Penelitian pendidikan matematika. bandung: Refika Aditama.

NCTM. (2000). Principles and standards for school mathematics. United States of America: The National Council of Teacher of Mathematics.

Hidayati. (2004). Cooperative Learning. Jakarta: Grasindo.

Hidayat, M. (2008). Pengembangan Pendidikan IPS SD 2008. UNS.

Luca, J. \&. (2002). Promoting Student Learning throung Peer Tutoring - A Case Study . ED-MEDIA 2002 World Conference on Educational Multimedia, Hypermedia \& Telecommunications., Proceedings (14 th, Denver, Colorado, June 24-29, 2002).

Duran, D. \&. (2005). Styles and sequences of cooperative interaction in fixed and reciprocal peer tutoring. Learning and Instruction, 15 (3), 179-199.

Vasy, E. (2010). The effectof peer Teaching in the Performance of students in Mathematics. EInternational scientific, Research Journal, 2, 161.

Within. ( 1992). Mathematics Task Centers, Proffesional Development and Problem Solving. In J.Wakefield and L. Velardi (Ed) Celebrating Mathematics Learning. Melbourne: The Mathematical Association of Victoria. 